\title{
Developmental milestones at one year for the offspring of mothers with congenital hypothyroidism: a population-based study
}

\author{
Juliane Léger 1,2,3, Anne Forhan ${ }^{4,5}$, Sophie Dos Santos', Béatrice Larroque ${ }^{6, \dagger}$, Emmanuel Ecosse ${ }^{1}$, \\ Marie-Aline Charles ${ }^{4,5}$ and Barbara Heude ${ }^{4,5}$ \\ ${ }^{1}$ Paediatric Endocrinology Diabetology Department, Assistance Publique-Hôpitaux de Paris, Robert Debré University Hospital, \\ Reference Center for Growth and Development Endocrine Diseases, Paris, France, ${ }^{2}$ Paris Diderot University, Sorbonne Paris Cité, Paris, \\ France, ${ }^{3}$ Institut National de la Santé et de la Recherche Médicale (INSERM), UMR 1141, DHU Protect, Paris, France, ${ }^{4}$ INSERM, UMR1153 \\ Epidemiology and Biostatistics Sorbonne Paris Cité Center, Early Origin of Child Health and Development Team \\ (ORCHAD), Paris, France, ${ }^{5}$ Paris Descartes University, Paris, France, and ${ }^{6}$ Epidemiology and Clinical Research Unit, \\ Beaujon Hospital, Clichy, France
}

${ }^{\dagger}$ (B Larroque is now deceased)
Correspondence should be addressed to $J$ Léger

Email

juliane.leger@aphp.fr

\begin{abstract}
Objective: Maternal thyroid dysfunction during pregnancy is associated with neurodevelopmental impairment in the offspring. No data are currently available for the offspring of patients treated early for congenital hypothyroidism (CH). The aim of this study was to investigate motor and language milestones at one year of age in a populationbased registry of children born to young women with $\mathrm{CH}$.

Design and methods: We assessed 110 children born to mothers with $\mathrm{CH}$, and 1367 children from the EDEN French population-based birth cohort study prospectively, at the age of one year, with identical questionnaires. Outcomes were assessed in terms of scores for childhood developmental milestones relating to mobility, motor coordination, communication, motricity and language skills.

Results: After adjustment for confounding factors, children born to mothers with $\mathrm{CH}$ were found to have a higher risk of poor motor coordination than those of the EDEN cohort (OR: 4.18, 95\% Cl: 2.52-6.93). No differences were identified for the other four domains investigated. Children born to mothers with gestational diabetes have a higher risk of low motor coordination score than their peers (OR: $2.10,95 \% \mathrm{CI}: 1.21-3.66)$. Children born to mothers with $\mathrm{TSH} \geq 10 \mathrm{IU} / \mathrm{L}$ during the first six months of pregnancy were more likely to have low motricity or communication skills scores than those born to mothers with lower TSH concentrations ( $56 \%$ vs $21 \%$ for each score, $P<0.04$ ).

Conclusions: Maternal $\mathrm{CH}$ may have slight adverse effects on some developmental milestones in the child at one year of age, particularly for children born to mothers with uncontrolled hypothyroidism. However, it remains unclear whether these adverse effects modify subsequent neurodevelopment.
\end{abstract}

\section{Introduction}

Adequate thyroid hormone (TH) levels are essential for human neurodevelopment during fetal and early postnatal life. During the first trimester of gestation, the only source
European Journal of

Endocrinology

(2018) 178, 471-480 www.eje-online.org

https://doi.org/10.1530/EJE-17-0855
(C) 2018 European Society of Endocrinology Printed in Great Britain of $\mathrm{TH}$ is the mother, with fetal thyroid function beginning at 12-14 weeks of gestation. However, the fetus continues to receive THs from the mother until term, and these maternal 
hormones play a protective role in fetal neurodevelopment, particularly during the first half of pregnancy (1). Maternal thyroid dysfunction during pregnancy is associated with adverse pregnancy and neonatal outcomes and poor neurocognitive outcomes in the child, particularly if the dysfunction occurs early in pregnancy $(2,3,4,5)$.

Congenital hypothyroidism (CH) affects one in every 3000 newborns in most countries. Its neurodevelopmental prognosis has been greatly improved by early neonatal management since the introduction of neonatal screening. If treatment is initiated late, the affected child may suffer severe brain damage. As a result, few patients with $\mathrm{CH}$ born before the introduction of neonatal screening went on to have children. We recently reported the first cohort study on pregnancy outcome in the $\mathrm{CH}$ patients who were treated early. We found that these patients had a higher risk of gestational hypertension, emergency cesarean delivery, induced labor for vaginal delivery and preterm delivery than the reference population (6). Disease etiology and severity were not associated with a higher risk of adverse outcomes. We also demonstrated that, although TH requirements and levothyroxine (L-T4) dose increased during pregnancy, serum thyroid-stimulating hormone (TSH) concentration was high $(\mathrm{TSH} \geq 5 \mathrm{IU} / \mathrm{L})$ in the first or second trimester in $40 \%$ of the pregnancies for which TSH assays were carried out. Moreover, in the same cohort, about half the patients reported no TSH test results at any time during pregnancy, suggesting that follow-up was non-optimal or that compliance with treatment was poor in these women. High serum TSH concentrations ( $\mathrm{TSH} \geq 10 \mathrm{IU} / \mathrm{L}$ ) during the first three to six months of pregnancy were associated with a higher risk of preterm delivery and fetal macrosomia (6).

In this context, the aim of this study was to describe the main developmental milestones reached at one year of age by the offspring of women with $\mathrm{CH}$, comparing these results with those for children from a population-based cohort. We also investigated whether the developmental milestones of these children were related to treatment quality before and during pregnancy and to the disease severity of maternal $\mathrm{CH}$.

\section{Patients and methods}

\section{Subjects}

$\mathrm{CH}$ group

This cohort of young adults was established for an investigation of the long-term consequences of being born with $\mathrm{CH}$ and has been described in detail elsewhere
$(7,8)$. It includes all patients $(n=1842)$ diagnosed with primary $\mathrm{CH}$ in France in the decade following the introduction of neonatal CH screening (1978-1988). A baseline health questionnaire was sent by regular mail and was completed by 1202 participants (in 2007-2008). All patients completing this questionnaire were then sent a self-administered questionnaire focusing on fecundity in each of the next two years. All women with $\mathrm{CH}$ declaring a pregnancy during this three-year period were invited, at the time of pregnancy declaration, to participate in this prospective study and to complete a questionnaire on pregnancy outcome. They were asked to return the pregnancy questionnaire within three months of the end of the pregnancy. This additional prospective study included all pregnancies ending after the completion of the initial questionnaire in 2007-2008. We also conducted a retrospective study, including all pregnancies ending before the completion of the first questionnaire. For the 570 pregnancies declared by 336 of the 860 women with $\mathrm{CH}, 381$ pregnancies $(n=207$ retrospective, $n=174$ prospective) ended in a singleton delivery after at least 22 weeks of gestation, with the newborns weighing at least $500 \mathrm{~g}$; three pregnancies produced twins. There were, therefore, 387 newborns in total. The other 186 pregnancies ended in a voluntary termination $(n=104)$, spontaneous miscarriage $(n=77)$, abortion for medical reasons $(n=4)$ or outcome was not determined $(n=1)(6)$. All women with $\mathrm{CH}$ with children reaching the age of one year during the study period $(n=174+43=217)$ were then asked to complete a questionnaire on the health status of the child at the age of one year (2007-2011) (Fig. 1).

\section{Study participation}

Questionnaires were completed prospectively for the 125 singletons reaching the age of one year during the study period who were born to women with $\mathrm{CH}$ agreeing to participate during the prospective $(n=89)$ or retrospective $(n=36)$ period (see flowchart on Fig. 1). No difference was found between the participating mothers and those who did not complete the questionnaire $(n=92)$ in terms of the etiology of hypothyroidism, age, education level, term at delivery of the child, prematurity, sex and birth weight of the child, presence or absence of gestational diabetes, hypertension during pregnancy, but the participants were less likely to have undergone cesarean section and more likely to have undergone induced labor than the nonparticipants (data not shown).

We selected one sibling per participating family (10 children were excluded and the child closest in age to 
A

EDEN population

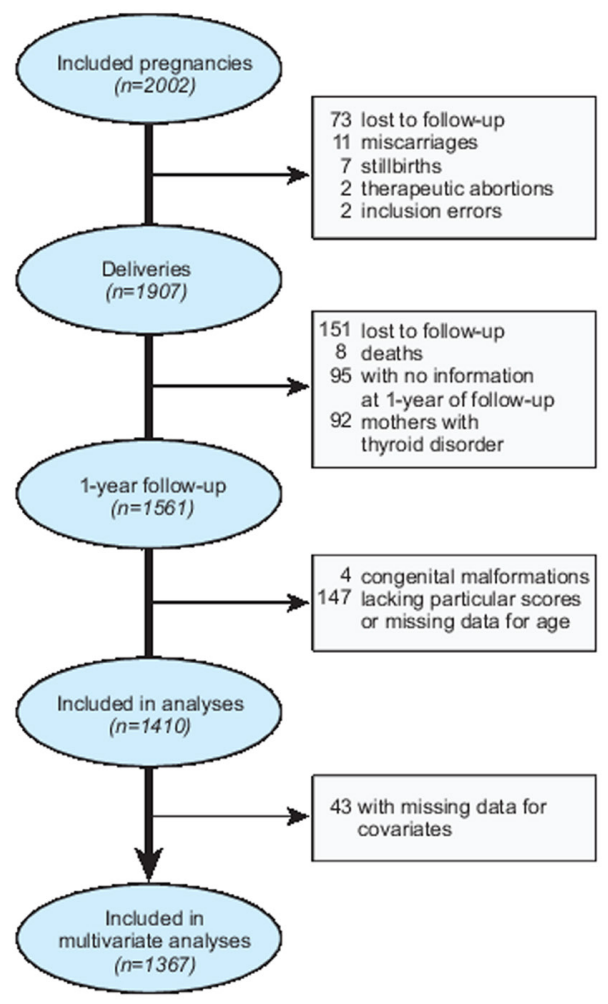

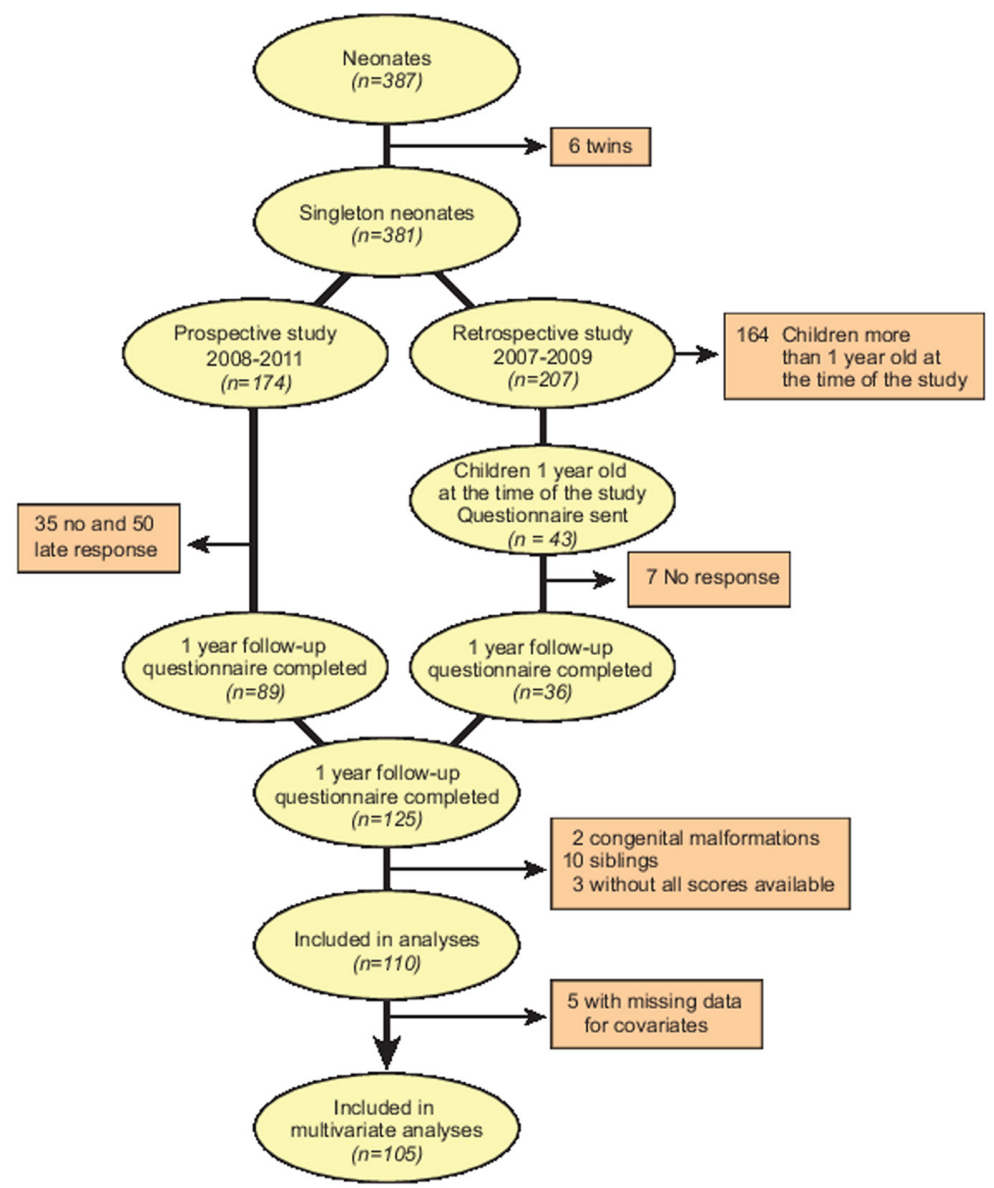

\section{Figure 1}

Flow chart of the study. Selection process for study participation for the EDEN cohort and the children of women with $\mathrm{CH}$..

one year at the time of questionnaire completion was retained). We excluded children with a history of chronic disease $(n=2 ; 1$ case of craniosynostosis and 1 case of $\mathrm{CH}$ with athyreosis), and children with missing data $(n=3$; not all scores were available). The study population of children born to mothers with $\mathrm{CH}$ consisted of 110 children. Data for covariates were missing for five of these children, so the final multivariate analysis included 105 children (Fig. 1).

The study was approved by the institutional review board of Paris North Hospitals, Paris 7 University, Assistance Publique Hôpitaux de Paris.

\section{The EDEN mother-child cohort}

The EDEN cohort was used as a control group. This group was established for an ongoing birth cohort study investigating the outcome of children in the general population (9). Participants were recruited between
2003 and 2006 from the pregnant women (24 weeks of amenorrhea) followed in two university hospital maternity units, in Poitiers and Nancy (France). The exclusion criteria were multiple pregnancies (e.g. twins), diabetes diagnosed before pregnancy, illiteracy or moving out of the region within the next three years. Overall, $53 \%$ of the women fulfilling the inclusion criteria agreed to participate. In total, 2002 women were included in the study, and 1907 were still being followed up at the time of the delivery.

\section{Study participation}

We excluded 92 children because of the presence or a history of thyroid disorder in the mother. Between birth and the age of one year, eight children died, 151 were lost to follow-up, and 95 did not attend the clinical examination at the age of one year. Thus, for 1561 infants of the EDEN study, an examination was performed by 
a trained midwife or a questionnaire completed by the parents was provided, when the child was one year old. Complete developmental milestone scores were available for 1410 of these children, and no data were missing for covariates for 1367 children (Fig. 1).

The study was approved by the Ethics Committee of Kremlin-Bicêtre Hospital and by the French Data Protection Authority. Written consent was obtained from the mothers for both themselves and their offspring.

\section{Data collection}

\section{$\mathrm{CH}$ group}

For the mothers with $\mathrm{CH}$, basic neonatal registration was completed at diagnosis, with further surveys during early adulthood $(7,8)$ and pregnancy $(6)$. Key variables relating to disease severity ( $\mathrm{CH}$ etiology, bone maturation delay at knee epiphyseal ossification centers and serum-free T4 (FT4) concentration at diagnosis), thyroid function and treatment quality during early adulthood and during pregnancy were defined a priori, as previously reported $(8,10)$. We assessed the quality of thyroid function control (TSH levels) and L-T4 dose for the 110 women with $\mathrm{CH}$, before pregnancy and in the first, second and third trimesters of pregnancy. The questionnaire for assessing the outcome of the child included items dealing with sociodemographic characteristics, chronic medical problems and the assessment of developmental milestones at 12 months.

\section{The EDEN population}

Sociodemographic data were collected during the first clinical examination of the mother, between 24 and 28 weeks of gestation and were updated with a selfadministered questionnaire completed by the parents at one year. Clinical and health data relating to pregnancy, delivery and the newborn were collected from the obstetric and pediatric records (11).

\section{Assessment of developmental milestones at 12 months}

For both the $\mathrm{CH}$ and EDEN cohorts, the assessment included items from the second version of the French Brunet-Lezine II developmental test created by Josse (12) and from the Bayley Scales of Infant Development (13). Most of the items were identical for the two populations and were grouped into five domains: mobility, coordination, language, motricity and communication. For the $\mathrm{CH}$ cohort, all questionnaires were completed by the parents. For the EDEN cohort, the first three domains were assessed with a questionnaire completed by the midwife during a semi-directed interview with the mother. The other two items were assessed from the questionnaire completed by the parents when the child was one year old (11). Scores were generated by summing the dichotomous responses to each item (Supplementary Table 1, see section on supplementary data given at the end of this article).

The mean was imputed for missing items when there were no more than two missing items for the coordination, motricity or communication scores for a particular child, and no more than three such items for the mobility and language scores. We set a threshold for each score, for comparisons of a lower development level with all the others. This threshold was based on the 20th percentile of the distribution of each composite score, to ensure that sufficient numbers of children were retained in the groups and to maintain statistical power. However, for coordination scores, the 20th percentile was not specific enough (i.e. it actually included more than 50\% of the children, due to the large number of ties), so we used the 10 th percentile instead.

\section{Other data collected}

The following common information was collected for the mothers of the $\mathrm{CH}$ and EDEN cohorts: age at delivery, educational achievement (more or less than 12 years of schooling), parity (primiparous vs others), hypertension during pregnancy, gestational diabetes, smoking, mode of delivery (spontaneous or induced vaginal delivery, programmed or emergency cesarean delivery) and marital status (living with or without a partner when the child was one year old). We collected the following information for the child: sex, birth weight, prematurity ( $<37$ weeks), exact age at follow-up assessments.

\section{Statistical analysis}

The results are expressed as means ( \pm s.E.M.) or medians (25-75th percentile) for quantitative variables, and as absolute numbers and percentages for qualitative variables. We first compared the offspring of the mothers in the $\mathrm{CH}$ cohort (exposed) with those from the EDEN cohort (non-exposed) for all maternal, delivery and child characteristics, in chi-squared and unadjusted Student's $t$ tests. Developmental milestone scores were also described and compared between the two populations in chisquared tests. We used nonparametric Fisher's exact tests 
to compare percentages for isolated items. The populations included in and excluded from the analysis were also compared within each cohort (CH or EDEN). Multivariate logistic regression models were used to predict the risk of each psychomotor and language outcome (low scores, as defined earlier). The cohort study and the adjustment variables were entered into the models as independent variables. Adjustment factors were selected for inclusion in the models if they differed between the $\mathrm{CH}$ cohort and a national representative sample of pregnancies (6) or were significantly $(P<0.10)$ associated with outcome in unexposed children (i.e. the children of the EDEN cohort).

We then compared developmental milestones according to thyroid function. We first compared women with serum TSH concentrations $\geq 5 \mathrm{mIU} / \mathrm{L}$ with women with serum TSH concentrations of 0.1-4.9 mIU/L, during each trimester of pregnancy. We then compared women with at least one serum TSH concentration $\geq 10 \mathrm{mIU} / \mathrm{L}$ during the first semester of pregnancy with those for whom all serum TSH concentrations were between $0.1 \mathrm{mIU} / \mathrm{L}$ and $9.9 \mathrm{mIU} / \mathrm{L}$ during this period. We used Fisher's exact tests for this comparison, due to the small numbers of subjects in each group.

All statistical analyses were performed with SAS 9.3 software (SAS Institute Inc, Cary, North Carolina).

\section{Results}

The characteristics of the study population are summarized in Table 1. Women with $\mathrm{CH}$ had a lower education level, were more likely to be younger and less likely to be living with partners than the women from the EDEN cohort. At the follow-up assessment, the children from $\mathrm{CH}$ mothers were slightly older, more likely to be looked after by their mothers or another family member and were more likely to be the first child born to the mother than the children in the EDEN cohort.

Comparisons of the characteristics of the mother and child between children included in and excluded from analyses within the $\mathrm{CH}$ and EDEN populations are shown in Supplementary Tables 2 and 3, respectively. The included mothers from the $\mathrm{CH}$ and the EDEN cohorts were less likely to be looking after the child themselves during the day, the included mothers from the $\mathrm{CH}$ group were more likely to be primiparous and those from the EDEN cohort were slightly older and had higher education levels than those excluded.

The one-year developmental milestone scores are described, with their thresholds, in Table 2, separately for the offspring of mothers with $\mathrm{CH}$ and for the children of the EDEN cohort. The rates of low motricity

Table 1 Maternal and infant characteristics, by study population, EDEN vs congenital hypothyroidism. Data are presented as $\%(n)$ or mean \pm S.E.M.

\begin{tabular}{|c|c|c|c|c|}
\hline & All $(n=1472)$ & EDEN $(n=1367)$ & CH $(n=105)$ & $\boldsymbol{P}$ \\
\hline Female & $47.1(693)$ & 47 (643) & $47.6(50)$ & 0.91 \\
\hline Exact age of the child at examination (months) & $12.2 \pm 0.02$ & $12.2 \pm 0.01$ & $12.5 \pm 0.14$ & $<0.0001$ \\
\hline Prematurity (yes) & $5.8(85)$ & $5.5(75)$ & $9.5(10)$ & 0.09 \\
\hline Birth weight (g) & $3292.1 \pm 13.0$ & $3292.6 \pm 13.5$ & $3285.9 \pm 50.5$ & 0.90 \\
\hline Main daytime caregiver & & & & 0.049 \\
\hline Nursery or childminder & $56.8(836)$ & $57.6(788)$ & $45.7(48)$ & \\
\hline Family & $10.1(149)$ & $9.8(134)$ & $14.3(15)$ & \\
\hline Mother & $33.1(487)$ & $32.6(445)$ & $40(42)$ & \\
\hline Maternal age at delivery (years) & $30.1 \pm 0.12$ & $30.3 \pm 0.13$ & $26.8 \pm 0.25$ & $<0.0001$ \\
\hline Primiparity (yes) & $46.8(689)$ & $46.2(631)$ & $55.2(58)$ & 0.07 \\
\hline Hypertension during pregnancy (yes) & $6.8(100)$ & $6.7(91)$ & $8.6(9)$ & 0.45 \\
\hline Gestational diabetes (yes) & $6.6(97)$ & $6.6(90)$ & $6.7(7)$ & 0.97 \\
\hline Maternal smoking during pregnancy (yes) & $23.0(338)$ & $23.2(317)$ & $20(21)$ & 0.46 \\
\hline Delivery mode & & & & 0.28 \\
\hline Spontaneous vaginal delivery & $67.1(988)$ & $67.6(924)$ & $61.0(64)$ & \\
\hline Induced vaginal delivery & $17.4(256)$ & $17.2(235)$ & $20.0(21)$ & \\
\hline Programmed cesarean delivery & $6.7(98)$ & $6.7(92)$ & $5.7(6)$ & \\
\hline Emergency cesarean delivery & $8.8(130)$ & $8.5(116)$ & $13.3(14)$ & \\
\hline Living with a partner at follow-up (yes) & $76.6(1127)$ & 77.5 (1059) & $64.8(68)$ & 0.003 \\
\hline Maternal education ( $>12$ years) & $56.4(830)$ & $57.4(784)$ & $43.8(46)$ & 0.007 \\
\hline Thyroid disease & & NA & & \\
\hline Athyreosis & & - & $30.5(32)$ & \\
\hline Ectopic gland & & - & $53.3(56)$ & \\
\hline Eutopic gland & & - & $13.3(14)$ & \\
\hline Unknown & & - & $2.9(3)$ & \\
\hline
\end{tabular}


Table 2 Development milestone scores: low score rates by study population, and odds ratios from multivariate logistic models. The EDEN population was used as the reference population.

\begin{tabular}{|c|c|c|c|c|c|c|c|c|}
\hline Outcome & Range & Threshold & Cases \% (n) & EDEN $(n=1367) \%(n)$ & $\begin{array}{c}\text { CH }(n=105 \\
(7.1 \%) \%(n)\end{array}$ & $\boldsymbol{P a}^{a}$ & $\begin{array}{l}\text { Adjusted OR* } \\
(95 \% \mathrm{Cl})\end{array}$ & $\boldsymbol{P}$ \\
\hline Mobility & $0-10$ & $\leq 5$ & $25.2(371)$ & $25.9(354)$ & $16.2(17)$ & 0.03 & $0.597(0.33-1.07)$ & 0.083 \\
\hline Motor coordination & $0-5$ & $\leq 2$ & $10.9(161)$ & $9.7(132)$ & $27.6(29)$ & $<0.0001$ & $4.181(2.52-6.93)$ & $<0.0001$ \\
\hline Language & $0-8$ & $\leq 5$ & $28.4(418)$ & 29.1 (398) & $19.0(20)$ & 0.03 & $0.735(0.43-1.26)$ & 0.26 \\
\hline Motricity & $0-6$ & $\leq 3$ & $26.0(383)$ & $26.2(358)$ & $23.8(25)$ & 0.64 & $0.988(0.59-1.64)$ & 0.96 \\
\hline Communication & $0-6$ & $\leq 4$ & $25.2(371)$ & $25.5(348)$ & $21.9(23)$ & 0.48 & $0.988(0.58-1.67)$ & 0.96 \\
\hline
\end{tabular}

aFisher's exact test; *OR adjusted for sex, age, prematurity, type of delivery, birth weight, main daytime time caregiver, maternal age at delivery, Primiparity, hypertension during pregnancy, gestational diabetes, maternal smoking during pregnancy, living with a partner, maternal education.

and communication scores did not differ significantly between these two populations. However, the offspring of mothers with $\mathrm{CH}$ were more likely than the children of the EDEN cohort to have low motor coordination skills, but less likely to have low mobility and language skills at 12 months of age.

After adjustment of the multivariate logistic models for relevant factors, the differences for mobility and language scores were no longer significant. The OR of the children of mothers with $\mathrm{CH}$ having a low score for motor coordination relative to children from the EDEN cohort was high (OR: 4.18; 95\% CI: 2.52-6.93) and significant $(P<0.0001)$. Similar results were obtained when the analysis was restricted to children of mothers with wellcontrolled $\mathrm{CH}$ (for motor coordination, OR: 3.46; 95\% CI: 1.6-7.51) $(P<0.001)$. The results of the multivariate logistic regression model for motor coordination are shown in Table 3. Exact age at assessment and gestational diabetes were the other two factors significantly associated with outcome. Children born to mothers with gestational diabetes had a higher risk of low motor coordination score than their peers $(\mathrm{OR}(95 \% \mathrm{CI})=2.10(1.21-3.66))$. None of the other characteristics of the pregnancy, the mother or the child considered were associated with the risk of poor motor coordination at 12 months of age.

The results of thyroid tests and L-T4 dose before and during pregnancy are described for mothers with $\mathrm{CH}$ in Table 4 . In 36 pregnancies, women with $\mathrm{CH}$ declared no TSH determination results during pregnancy. Serum TSH concentration was high ( $\mathrm{TSH} \geq 5 \mathrm{mIU} / \mathrm{L}$ ) during the first trimester of pregnancy in 18 women and during the second trimester of pregnancy in 17 women, corresponding to $25 \%$ and $26 \%$, respectively, of the women for whom TSH assays were carried out. Overall, $41 \%(n=31)$ of these

Table 3 Multivariate logistic regression model for the risk of poor coordination at the age of one year.

\begin{tabular}{|c|c|c|c|}
\hline & OR & $95 \% \mathrm{Cl}$ & $\boldsymbol{P}$ \\
\hline Cohort Study: $\mathrm{CH}$ vs EDEN & 4.181 & $(2.52-6.93)$ & $<0.0001$ \\
\hline Female & 0.995 & $(0.71-1.4)$ & 0.98 \\
\hline Exact age (days) & 0.989 & $(0.98-1)$ & 0.023 \\
\hline Prematurity (yes) & 1.584 & $(0.78-3.23)$ & 0.21 \\
\hline Birth weight $(100 \mathrm{~g})$ & 0.978 & $(0.94-1.02)$ & 0.27 \\
\hline \multicolumn{4}{|l|}{ Main daytime caregiver } \\
\hline Nursery or childminder & 0.901 & $(0.61-1.34)$ & 0.61 \\
\hline Family & 0.808 & $(0.43-1.53)$ & 0.51 \\
\hline Mother & 1 & & \\
\hline Maternal age at delivery (5 years) & 1.103 & $(0.89-1.36)$ & 0.37 \\
\hline Primiparity (yes) & 0.969 & $(0.66-1.41)$ & 0.87 \\
\hline Hypertension during pregnancy (yes) & 0.731 & $(0.36-1.49)$ & 0.39 \\
\hline Gestational diabetes (yes) & 2.102 & $(1.21-3.66)$ & 0.009 \\
\hline \multicolumn{4}{|l|}{ Delivery mode } \\
\hline Spontaneous vaginal delivery & 1 & & \\
\hline Induced vaginal delivery & 1.032 & $(0.65-1.63)$ & 0.89 \\
\hline Programmed cesarean delivery & 1.063 & $(0.55-2.05)$ & 0.86 \\
\hline Emergency cesarean delivery & 1.139 & $(0.63-2.06)$ & 0.67 \\
\hline Maternal smoking during pregnancy (yes) & 0.822 & $(0.53-1.28)$ & 0.38 \\
\hline Living with partner (yes) & 1.181 & $(0.77-1.8)$ & 0.44 \\
\hline Maternal education: ( $>12$ years) & 1.069 & $(0.94-1.21)$ & 0.30 \\
\hline
\end{tabular}

www.eje-online.org 
Table 4 Thyroid function and levothyroxine dose for women with congenital hypothyroidism ( $n=110)$, before pregnancy, and in the first, second and third trimesters of pregnancy. Data are presented as \% $(n)$ or median (25-75th percentile).

\begin{tabular}{cc}
\hline & $\begin{array}{c}\text { At the time of the baseline } \\
\text { questionnaire* }\end{array}$ \\
\cline { 1 - 1 }$(\mathrm{mlU} / \mathrm{L})$ & $0.8(0.2-1.7)(n=42)$ \\
$\mathrm{TSH}<0.1$ & $16.7(7)$ \\
$\mathrm{TSH} 0.1-4.9$ & $78.6(33)$ \\
$\mathrm{TSH} 5.0-9.9$ & $2.4(1)$ \\
$\mathrm{TSH} \geq 10$ & $2.4(1)$ \\
Levothyroxine dose & $137(125-163)$ \\
$(\mu \mathrm{g} /$ day) & $(n=54)$ \\
\hline
\end{tabular}

\begin{tabular}{c}
\hline First trimester \\
\hline $3(1.3-4.8)(n=73)$ \\
$6.8(5)$ \\
$68.5(50)$ \\
$19.2(14)$ \\
$5.5(4)$ \\
$150(133-175)$ \\
$(n=102)$ \\
\hline
\end{tabular}

\begin{tabular}{c}
\hline Second trimester \\
\hline $3(1.7-5)(n=66)$ \\
$3.0(2)$ \\
$71.2(47)$ \\
$18.2(12)$ \\
$7.6(5)$ \\
$162(150-183)$ \\
$(n=103)$ \\
\hline
\end{tabular}

\begin{tabular}{c}
\hline Third trimester \\
\hline $1.9(0.9-3.3)(n=57)$ \\
$1.8(1)$ \\
$89.5(51)$ \\
$5.3(3)$ \\
$3.5(2)$ \\
$175(150-200)$ \\
$(n=102)$ \\
\hline
\end{tabular}

*In the three months before pregnancy.

women had at least one high TSH concentration during pregnancy. Levothyroxine requirements increased from a median of 137 (125-163) before pregnancy to 175 (150200) $\mu$ g per day during the third trimester of pregnancy.

No association was found between any of the five developmental domains and any of the parameters relating to the quality of thyroid function control in the mother at any period considered, as assessed with a threshold of $5 \mathrm{mIU} / \mathrm{L}$ for serum TSH concentration (values above this threshold being considered to be high, whereas those between 0.1 and $4.9 \mathrm{mIU} / \mathrm{L}$ were considered to be normal (results not shown)).

Nine women had at least one very high serum TSH value ( $\geq 10 \mathrm{mIU} / \mathrm{L}$ ) during the first semester of pregnancy, corresponding to $12 \%$ of women with at least one TSH assay. The offspring of these mothers were more likely to have low scores for motricity and communication skills than their 62 peers with serum TSH concentrations from 0.1 to $9.9 \mathrm{mIU} / \mathrm{L}$ (56 vs $21 \%, P<0.04$, for both motricity and communication skills).

None of the developmental outcome scores was associated with $\mathrm{CH}$ severity in the mother, as assessed by the type of $\mathrm{CH}$ (athyreosis, ectopic or eutopic gland), bone maturation delay at the time of diagnosis (with at least one knee epiphyseal ossification center absent in the most severe forms) and serum FT4 levels at diagnosis (data not shown).

\section{Discussion}

This prospective observational study is, to our knowledge, the first to have examined the neurodevelopmental outcomes of children born to mothers with $\mathrm{CH}$ from a national cohort study of women treated early, through the neonatal screening program. Milestones for mobility, communication, motricity and language skills were similar, but there was a higher risk of low motor coordination score in one-year-old children born to mothers with $\mathrm{CH}$ than in children of the same age in the control population. Gestational diabetes was also strongly associated with this outcome, as it more than doubled the risk of low motor coordination score, but this condition was taken into account in the model and was not responsible for the association between $\mathrm{CH}$ and coordination.

Previous studies have shown a slightly low total motor impairment score, including manual dexterity during childhood, in patients treated early for severe $\mathrm{CH}(14,15$, 16), but such impairment is unlikely to be involved in the association found in our study.

Other observational studies have suggested an association between gestational diabetes, particularly for women whose blood glucose levels did not remain optimal and impaired neurodevelopment in the offspring at the age of one to two years, with significant heterogeneity in children assessed at the ages of 3-12 years (17). These findings have led to the hypothesis that gestational diabetes may have a major impact on the cognitive function of the offspring very early in life, with this impact gradually decreasing as the child grows up. No causal relationship has been established, but it has been suggested that the mother being overweight or obese may have a synergistic effect in the triggering of adverse neurodevelopmental outcomes in children $(17,18)$. It should be borne in mind that women with $\mathrm{CH}$ are more likely to be overweight/ obese than the general population (6).

We can speculate that this impairment at one year of age may have little impact on subsequent cognitive development, as recently observed in the children from the EDEN cohort studied longitudinally for five to six years. In the EDEN study, developmental milestones at one year predicted only a small proportion of the intellectual quotient (IQ) at the age of five to six years; early language skills, which were preserved in our population of children 
born to mothers with $\mathrm{CH}$, were stronger predictors of IQ than the other cognitive domains considered (19).

Another interesting finding of our study, albeit based on the analysis of only a small number of children, was the association between low motricity and communication skill scores at the age of one year in the child and the obtainment of at least one serum TSH concentration $\geq 10 \mathrm{mIU} / \mathrm{L}$ during the first semester of pregnancy. Smaller increases in serum TSH levels had no such effect. No other association was observed with subclinical hypothyroidism (5-9.9 mIU/L) at any time during pregnancy, inadequate treatment before pregnancy (considered to reflect chronic treatment inadequacy) or disease etiology or $\mathrm{CH}$ severity in the mother.

These results should be considered in light of the known importance of thyroid control in women with acquired hypothyroidism, particularly during the first half of pregnancy, as a risk factor for neurodevelopmental impairment, as shown in most previous studies $(2,4,5$, $20,21,22,23)$. The evidence of a link is weaker in cases of subclinical hypothyroidism or hypothyroxinemia in pregnancy $(7,24,25,26)$. We found that LT-4 dose increased, as expected, during pregnancy, in this cohort of women with $\mathrm{CH}$, and that more than two thirds of the TSH measurements reported during pregnancy indicated adequate control of thyroid function. However, the relatively small number of women with uncontrolled thyroid function described here (either with serum TSH concentration slightly above the upper limit of the reference range or overt hypothyroidism, suggesting non-optimal management or poor compliance with treatment), made it difficult to investigate the association of maternal thyroid dysfunction with the potential risk of adverse developmental milestones at one year in the offspring more fully. Thyroid function was not assessed during pregnancy in some of the patients and was assessed at different time points during pregnancy in the patients investigated. The normal or high serum TSH concentrations during pregnancy reported here may have been transient and not representative of $\mathrm{TH}$ availability during the crucial first trimester or first half of gestation or throughout pregnancy. We cannot, therefore, exclude the possibility that some of the women received inadequate treatment throughout pregnancy. This factor may be particularly important, given that inadequate treatment, resulting in subclinical or overt hypothyroidism, may affect pregnancy outcomes and the neurodevelopmental outcomes of the offspring $(2,5,20,21,22,23,26)$. Further studies are therefore required, to determine whether thyroid function during pregnancy affects the developmental milestones, at the age of one year, of the offspring of women managed and treated early for $\mathrm{CH}$, to assess the time-dependent effects of maternal thyroid function on the neurodevelopmental outcome of the child and to determine whether the congenital nature of the mother's disease plays a role.

The strengths of our study include the populationbased design of the cohorts, the large number of women with $\mathrm{CH}$ included, the exhaustive national coverage, the comparative design with an appropriate control group and the control for multiple confounding factors in both populations. Moreover, our analysis of this sample provides the first information about the recurrence of $\mathrm{CH}$ in the offspring of mothers with $\mathrm{CH}$ since the introduction of screening programs. Only one of the children was found to have $\mathrm{CH}$, due to athyreosis; this child was born to a mother with an ectopic thyroid gland. This finding suggests that the risk of giving birth to a child with $\mathrm{CH}$ is no higher than expected from our previous report. Indeed, we previously showed that $2 \%$ of $\mathrm{CH}$ patients with abnormal thyroid development have a positive familial history and that ectopic thyroid gland may also occur in families affected by athyreosis, confirming the continuum of abnormalities in thyroid development (27, 28). Moreover, contrary to reports for the $\mathrm{CH}$ population (28), no significant numbers of extrathyroidal congenital malformation were reported in the offspring of this sample.

However, our study also had several limitations. The control group included only subjects born in northeastern or central France, with a slightly higher level of education than for the national population (9), whereas the children born to mothers with $\mathrm{CH}$ belonged to a nationwide cohort (6). Despite the well-known risk of a lower educational level already reported for this population with $\mathrm{CH}$ (8), we cannot, therefore, entirely exclude the possibility of residual confounding bias due to the higher educational level of the reference population. Given the observational nature of data collection, we cannot exclude the possibility that some of the mothers with $\mathrm{CH}$ incorrectly gave negative (or positive) responses to certain questions, potentially leading to an underestimation (overestimation) of the number of observed milestones. However, this limitation is unlikely to apply, as we asked several questions for each domain and estimated a score from the answers to all questions within each domain, as in the reference population. Nevertheless, the information for each domain and the use of a self-reported questionnaire may also have resulted in misclassification. We used similar questionnaires in both populations, but, 
for the reference population, the questions were asked by a midwife rather than directly answered by the mothers, for three domains: language, coordination and motor ability. Reporting bias cannot be excluded, but is unlikely to have been systematic and differential, because differences were observed only for the coordination domain (11). Another potential limitation of this study is that, despite the exclusion of reported thyroid diseases from the reference population, no data were available for iodine status, which may affect brain development in the child $(5,29)$. This study was performed in a population with proven iodine sufficiency, but iodine-deficient women and women with high iodine intake may have been present in the study populations (30), with potential effects on the association between thyroid function during pregnancy and neurodevelopmental outcome in the child.

In conclusion, the results of this observational study suggest that maternal $\mathrm{CH}$ may have mild adverse effects on some of the developmental milestones of the child at one year of age. The clinical implications are limited, but the observed difference suggest that the control of thyroid function during pregnancy may be an important determinant of early neurodevelopment. Further studies are required to confirm these findings and to investigate cognitive function in the longer term, with a view to determining whether subtle disadvantages persist during childhood in the children born to mothers with $\mathrm{CH}$.

Supplementary data

This is linked to the online version of the paper at https://doi.org/10.1530/ EJE-17-0855.

\section{Declaration of interest}

The authors declare that there is no conflict of interest that could be perceived as prejudicing the impartiality of this study.

\section{Funding}

This study was supported by the French Ministry of Health (Programme Hospitalier de Recherche Clinique AOM 05011) and by the Pfizer Foundation for Children and Adolescents. We acknowledge all funding sources for the EDEN study: The Foundation for Medical Research (FRM), the National Agency for Research (ANR), the National Institute for Research in Public Health (IRESP: TGIR cohorte santé 2008 program), the French Ministry of Health (DGS), the French Ministry of Research, INSERM Bone and Joint Diseases National Research (PRO-A) and Human Nutrition National Research Programs, Paris-Sud University, Nestlé, the French National Institute for Population Health Surveillance (InVS), the French National Institute for Health Education (INPES), the European Union FP7 programs (FP7/2007-2013, HELIX, ESCAPE, ENRIECO, Medall projects), the Diabetes National Research Program (through a collaboration with the French Association of Diabetic Patients (AFD)), the French Agency for Environmental Health Safety (now ANSES), the Mutuelle Générale de I'Education Nationale (a complementary health insurance company, MGEN), the French National Agency for Food Security, and the French-Speaking Association for the Study of Diabetes and Metabolism (ALFEDIAM). The funders had no influence of any kind on the analysis or interpretation of results. Data collection and analysis, data interpretation and the decision to submit the paper for publication were the responsibility of the authors alone.

\section{Acknowledgments}

The authors thank Professor Michel Roussey, Head of the Association Française pour le Dépistage et la Prévention des Handicaps de l'Enfant (AFDPHE) for helping to organize the study, all patients for participating in the study and all the physicians involved in the follow-up of patients. We thank the members of the EDEN mother-child cohort study group: I Annesi-Maesano, J Y Bernard, J Botton, M A Charles, P Dargent-Molina, $B$ de Lauzon-Guillain, $P$ Ducimetière, $M$ de Agostini, B Foliguet, A Forhan, X Fritel, A Germa, V Goua, R Hankard, B Heude, M Kaminski, B Larroque, N Lelong, J Lepeule, G Magnin, L Marchand, C Nabet, F Pierre, R Slama, M J Saurel-Cubizolles, M Schweitzer, O Thiebaugeorges.

\section{References}

1 Morreale de Escobar G, Obregon MJ \& Escobar del Rey F. Role of thyroid hormone during early brain development. European Journal of Endocrinology 2004151 U25-U37. (https://doi.org/10.1530/ eje.0.151U025)

2 Pop VJ, Kuijpens JL, van Baar AL, Verkerk G, van Son MM, de Vijlder JJ, Vulsma T, Wiersinga WM, Drexhage HA \& Vader HL. Low maternal free thyroxine concentrations during early pregnancy are associated with impaired psychomotor development in infancy. Clinical Endocrinology 199950 149-155. (https://doi.org/10.1046/ j.1365-2265.1999.00639.x)

3 Teng W, Shan Z, Patil-Sisodia K \& Cooper DS. Hypothyroidism in pregnancy. Lancet Diabetes and Endocrinology $20131228-237$. (https://doi.org/10.1016/S2213-8587(13)70109-8)

4 Korevaar TI, Muetzel R, Medici M, Chaker L, Jaddoe VW, de Rijke YB, Steegers EA, Visser TJ, White T, Tiemeier $\mathrm{H}$ et al. Association of maternal thyroid function during early pregnancy with offspring IQ and brain morphology in childhood: a population-based prospective cohort study. Lancet Diabetes and Endocrinology 20164 35-43. (https://doi.org/10.1016/S2213-8587(15)00327-7)

5 Alexander EK, Pearce EN, Brent GA, Brown RS, Chen H, Dosiou C, Grobman WA, Laurberg P, Lazarus JH, Mandel SJ et al. 2017 Guidelines of the American Thyroid Association for the diagnosis and management of thyroid disease during pregnancy and the postpartum. Thyroid 201727 315-389.

6 Leger J, dos Santos S, Larroque B \& Ecosse E. Pregnancy outcomes and relationship to treatment adequacy in women treated early for congenital hypothyroidism: a longitudinal population-based study. Journal of Clinical Endocrinology and Metabolism 2015100 860-869. (https://doi.org/10.1210/jc.2014-3049)

7 Hassani Y, Larroque B, Dos Santos S, Ecosse E, Bouyer J \& Leger J. Fecundity in young adults treated early for congenital hypothyroidism is related to the initial severity of the disease: a longitudinal population-based cohort study. Journal of Clinical Endocrinology and Metabolism 201297 1897-1904. (https://doi. org/10.1210/jc.2011-3286)

8 Leger J, Ecosse E, Roussey M, Lanoe JL \& Larroque B. Subtle health impairment and socioeducational attainment in young adult patients with congenital hypothyroidism diagnosed by neonatal screening: a longitudinal population-based cohort study. Journal of Clinical Endocrinology and Metabolism 201196 1771-1782. (https:// doi.org/10.1210/jc.2010-2315) 
9 Heude B, Forhan A, Slama R, Douhaud L, Bedel S, SaurelCubizolles MJ, Hankard R, Thiebaugeorges O, De Agostini M, AnnesiMaesano I et al. Cohort profile: The EDEN mother-child cohort on the prenatal and early postnatal determinants of child health and development. International Journal of Epidemiology 201645 353-363. (https://doi.org/10.1093/ije/dyv151)

10 Leger J, Larroque B \& Norton J. Influence of severity of congenital hypothyroidism and adequacy of treatment on school achievement in young adolescents: a population-based cohort study. Acta Paediatrica 200190 1249-1256. (https://doi. org/10.1111/j.1651-2227.2001.tb01570.x)

11 Guedeney A, Forhan A, Larroque B, de Agostini M, Pingault JB \& Heude B. Social withdrawal behaviour at one year of age is associated with delays in reaching language milestones in the EDEN MotherChild Cohort Study. PLoS ONE 201611 e0158426. (https://doi. org/10.1371/journal.pone.0158426)

12 Josse D. Revised Brunet-Lezine Test: Infancy Psychomotor Development Scale (Brunet-Lezine Révisée: Echelle de Développement Psychomoteur de la Première Enfance). Paris, France: Etablissement d'Applications Psychotechniques, 1997.

13 Bayley N. Bayley Scales of Infant and Toddler Development, 3rd ed. San Antonio, TX: Harcourt Assessment, 2006.

14 Fuggle PW, Grant DB, Smith I \& Murphy G. Intelligence, motor skills and behaviour at 5 years in early-treated congenital hypothyroidism. European Journal of Pediatrics 1991150 570-574. (https://doi. org/10.1007/BF02072209)

15 Kooistra L, Laane C, Vulsma T, Schellekens JM, van der Meere JJ \& Kalverboer AF. Motor and cognitive development in children with congenital hypothyroidism: a long-term evaluation of the effects of neonatal treatment. Journal of Pediatrics 1994124 903-909. (https:// doi.org/10.1016/S0022-3476(05)83178-6)

16 Kempers MJ, van der Sluijs Veer L, Nijhuis-van der Sanden RW, Lanting CI, Kooistra L, Wiedijk BM, Last BF, de Vijlder JJ, Grootenhuis MA \& Vulsma T. Neonatal screening for congenital hypothyroidism in the Netherlands: cognitive and motor outcome at 10 years of age. Journal of Clinical Endocrinology and Metabolism 2007 92 919-924. (https://doi.org/10.1210/jc.2006-1538)

17 Camprubi Robles M, Campoy C, Garcia Fernandez L, LopezPedrosa JM, Rueda R \& Martin MJ. Maternal diabetes and cognitive performance in the offspring: a systematic review and meta-analysis. PLoS ONE 201510 e0142583. (https://doi.org/10.1371/journal. pone.0142583)

18 Daraki V, Roumeliotaki T, Koutra K, Georgiou V, Kampouri M, Kyriklaki A, Vafeiadi M, Papavasiliou S, Kogevinas M \& Chatzi L. Effect of parental obesity and gestational diabetes on child neuropsychological and behavioral development at 4 years of age: the Rhea mother-child cohort, Crete, Greece. European Child and Adolescent Psychiatry 201726 703-704. (https://doi.org/10.1007/ s00787-016-0934-2)

19 Peyre H, Charkaluk ML, Forhan A, Heude B \& Ramus F. Do developmental milestones at 4, 8, 12 and 24 months predict IQ at 5-6 years old? Results of the EDEN mother-child cohort. European Journal of Paediatric Neurology 201721 272-279. (https://doi. org/10.1016/j.ejpn.2016.11.001)
20 Haddow JE, Palomaki GE, Allan WC, Williams JR, Knight GJ, Gagnon J, O'Heir CE, Mitchell ML, Hermos RJ, Waisbren SE et al. Maternal thyroid deficiency during pregnancy and subsequent neuropsychological development of the child. New England Journal of Medicine 1999341 549-555. (https://doi.org/10.1056/ NEJM199908193410801)

21 Pop VJ, Brouwers EP, Vader HL, Vulsma T, van Baar AL \& de Vijlder JJ. Maternal hypothyroxinaemia during early pregnancy and subsequent child development: a 3-year follow-up study. Clinical Endocrinology 200359 282-288. (https://doi.org/10.1046/j.13652265.2003.01822.x)

22 Ghassabian A, Henrichs J \& Tiemeier H. Impact of mild thyroid hormone deficiency in pregnancy on cognitive function in children: lessons from the Generation R Study. Best Practice and Research: Clinical Endocrinology and Metabolism 201428 221-232. (https://doi. org/10.1016/j.beem.2013.04.008)

23 Smit BJ, Kok JH, Vulsma T, Briet JM, Boer K \& Wiersinga WM. Neurologic development of the newborn and young child in relation to maternal thyroid function. Acta Paediatrica 200089 291-295. (https://doi.org/10.1111/j.1651-2227.2000.tb18424.x)

24 Lazarus JH, Bestwick JP, Channon S, Paradice R, Maina A, Rees R, Chiusano E, John R, Guaraldo V, George LM et al. Antenatal thyroid screening and childhood cognitive function. New England Journal of Medicine 2012366 493-501. (https://doi.org/10.1056/ NEJMoa1106104)

25 Casey BM, Thom EA, Peaceman AM, Varner MW, Sorokin Y, Hirtz DG, Reddy UM, Wapner RJ, Thorp JM Jr, Saade G et al. Treatment of subclinical hypothyroidism or hypothyroxinemia in pregnancy. New England Journal of Medicine 2017376 815-825. (https://doi.org/10.1056/NEJMoa1606205)

26 Cooper DS \& Pearce EN. Subclinical hypothyroidism and hypothyroxinemia in pregnancy - still no answers. New England Journal of Medicine 2017376 876-877. (https://doi.org/10.1056/ NEJMe1615312)

27 Castanet M, Lyonnet S, Bonaiti-Pellie C, Polak M, Czernichow P \& Leger J. Familial forms of thyroid dysgenesis among infants with congenital hypothyroidism. New England Journal of Medicine 2000 343 441-442. (https://doi.org/10.1056/NEJM200008103430614)

28 Castanet M, Polak M, Bonaiti-Pellie C, Lyonnet S, Czernichow P $\&$ Leger J. Nineteen years of national screening for congenital hypothyroidism: familial cases with thyroid dysgenesis suggest the involvement of genetic factors. Journal of Clinical Endocrinology and Metabolism 200186 2009-2014.

29 Bath SC, Steer CD, Golding J, Emmett P \& Rayman MP. Effect of inadequate iodine status in UK pregnant women on cognitive outcomes in their children: results from the Avon Longitudinal Study of Parents and Children (ALSPAC). Lancet 2013382 331-337. (https://doi.org/10.1016/S0140-6736(13)60436-5)

30 Ghassabian A, Steenweg-de Graaff J, Peeters RP, Ross HA, Jaddoe VW, Hofman A, Verhulst FC, White T \& Tiemeier H. Maternal urinary iodine concentration in pregnancy and children's cognition: results from a population-based birth cohort in an iodinesufficient area. BMJ Open 20144 e005520. (https://doi.org/10.1136/ bmjopen-2014-005520)

Received 16 October 2017

Revised version received 1 February 2018

Accepted 1 March 2018 